\section{JMJ14, a JmjC domain protein, is required for RNA silencing and cell-to-cell movement of an RNA silencing signal in Arabidopsis}

\author{
Iain R. Searle, ${ }^{1,2}$ Olga Pontes, ${ }^{3}$ Charles W. Melnyk, ${ }^{1,2}$
} Lisa M. Smith, ${ }^{2,4}$ and David C. Baulcombe ${ }^{1,2,5}$

${ }^{1}$ Plant Sciences Department, Cambridge University, Cambridge CB2 3EA, United Kingdom; ${ }^{2}$ The Sainsbury Laboratory, Norwich NR4 7UH, United Kingdom; ${ }^{3}$ Biology Department, Washington University, St. Louis, Missouri 63130, USA

JMJ14 is a histone H3 Lys4 (H3K4) trimethyl demethylase that affects mobile RNA silencing in an Arabidopsis transgene system. It also influences CHH DNA methylation, abundance of endogenous transposon transcripts, and flowering time. JMJ14 acts at a point in RNA silencing pathways that is downstream from RNA-dependent RNA polymerase 2 (RDR2) and Argonaute 4 (AGO4). Our results illustrate a link between RNA silencing and demethylation of histone $\mathrm{H} 3$ trimethylysine. We propose that JMJ14 acts downstream from the Argonaute effector complex to demethylate histone $\mathrm{H} 3 \mathrm{~K} 4$ at the target of RNA silencing.

Supplemental material is available at http://www.genesdev.org.

Received February 14, 2010; revised version accepted March 26, 2010 .

In plants, RNA silencing of a non-cell-autonomous nature is evident in transgenic and virus-infected plants. Transgene silencing may initiate spontaneously or be induced in localized regions and subsequently spread throughout the plant (Palauqui et al. 1997; Voinnet and Baulcombe 1997; Voinnet et al. 1998). Similarly, virusinduced silencing has effects beyond the infected tissue, and it is thought that the silencing signal is an RNA species. This RNA would move short distances through the plasmodesmata and systemically through the phloem (Voinnet et al. 1998).

Movement of the silencing signal is also associated with epigenetic modifications such as DNA cytosine methylation at targeted DNA loci. This RNA-directed DNA methylation (RdDM) is characterized by methylation of cytosines in all sequence contexts: $\mathrm{CG}, \mathrm{CHG}$, and $\mathrm{CHH}$, where $\mathrm{H}$ is $\mathrm{A}, \mathrm{T}$, or $\mathrm{C}$. In contrast, RNA-independent methylation affects those residues that are present in a CG or CHG context. Various DNA cytosine meth-

[Keywords: RNA silencing; Arabidopsis; siRNAs; chromatin; histone demethylase]

${ }^{4}$ Present address: Department of Molecular Biology, Max Planck Institute for Developmental Biology, Tübingen 72076, Germany.

${ }^{5}$ Corresponding author.

E-MAIL dcb40@cam.ac.uk; FAX 44-122-339953.

Article is online at http://www.genesdev.org/cgi/doi/10.1101/gad.579910. yltransferases, histone-modifying enzymes, and nuclearlocalized RNA silencing proteins are required for RdDM (Cao and Jacobsen 2002b; Jackson et al. 2002; Li et al. 2006; Pontes et al. 2006). In addition, several plantspecific proteins are required, most notably subunits of two novel RNA polymerases termed Pol IV and Pol V (Herr 2005; Kanno et al. 2005b). Pol IV and Pol V share the same second-largest subunit, NRPD2/NRPE2, but are distinguished by their unique largest subunits, NRPD1 and NRPE1, respectively. Many of the other subunits are shared with Pol II (Huang et al. 2009; Lahmy et al. 2009). Pol IV produces and/or amplifies the small RNA trigger, whereas Pol V acts downstream from this step to facilitate de novo methylation at the small RNA targeted site (Kanno et al. 2005a).

$\mathrm{RdDM}$ is also associated with histone modification, as well as DNA methylation at Arabidopsis loci, where CHG methylation by CHROMOMETHYLASE 3 (CMT3) is dependent on an SRA-SET domain protein, KRYPTONITE (KYP/SUVH4) (Cao and Jacobsen 2002a; Jackson et al. 2002). KYP catalyzes methylation of histone H3 Lys9 (H3K9), providing a binding site for the chromodomain of CMT3 (Lindroth et al. 2004). Two other SRA-SET proteins (SUVH5 and SUVH6) that methylate H3K9 also contribute (Ebbs et al. 2005; Ebbs and Bender 2006). The relationship between histone and DNA modification also operates in the reverse direction. Thus, KYP and SUVH6 bind directly to DNA methylated at CHG sites through their SRA domains (Johnson et al. 2007).

A link between histone modification and DNA methylation is implied not only by the phenotype of mutations in SRA-SET proteins, but also by the function of Jumonji $\mathrm{C}(\mathrm{JmjC})$ proteins found in diverse eukaryotes, including humans, yeast, and plants that are $\mathrm{H} 3$ lysine demethylases. Arabidopsis encodes $21 \mathrm{JmjC}$ domain proteins, including some that may affect DNA methylation (Lu et al. 2008). One of them (IBM1/JMJ25) prevents the spread of DNA methylation at certain genomic loci (Saze et al. 2008). KDM1/LSD1-another protein in this groupdemethylates methylated H3K4 (H3K4me1) and dimethylated H3K4 (H3K4me2) residues (Shi et al. 2004). Other JmjC group proteins (ELF6/JMJ11 and REF6/JMJ12) either delay or accelerate flowering time, and they demethylate dimethylated/trimethylated H3K9 (H3K9me2/3) and H3K36me2/3, respectively (Noh et al. 2004). MEE27/JMJ25 is required for embryo development, and belongs to the KDM5/JARID1 subgroup of JmjC proteins (Pagnussat et al. 2005). KDM5/JARID1 proteins are histone demethylases using H3K4me1, H3K4me2, and H3K4me3 substrates (Christensen et al. 2007; Iwase et al. 2007; Lee et al. 2007; Seward et al. 2007).

In this study, we describe genetic evidence to implicate a KDM5/JARID1 protein, JMJ14, in RNA silencing. It is associated with a mobile signal of silencing in a pathway that is associated with methylation of the DNA at the target locus of RNA silencing. JMJ14 is also implicated in silencing of endogenous transposable elements in a pathway that is dependent on RNA-dependent RNA polymerase 2 (RDR2) and Argonaute 4 (AGO4) and control of flowering time. Based on an epistasis analysis in which the subcellular location of RDR2 and AGO4 location was assayed in wild-type and jmj14 plants, we propose that JMJ14 acts downstream from the Argonaute effector 
complex to demethylate histone $\mathrm{H} 3 \mathrm{~K} 4 \mathrm{me} 3$ residues at the target of RNA silencing.

\section{Results and Discussion}

\section{A JmjC domain-containing protein, JAM39/JMJ14, is required for RNA silencing}

To identify RNA silencing components involved in cellto-cell movement of an RNA silencing signal in Arabidopsis, we used plants in which a transgenic photobleaching phenotype was due to spread of an RNA silencing signal into the mesophyll from the phloem (Smith et al. 2007). The target of silencing in this system was the endogenous phytoene desaturase $(P D S)$, and we refer to the silencer transgene as JAP (Smith et al. 2007). We demonstrated previously that chromatin silencing components NRPD1 (nuclear Pol IV), RDR2, and CLSY1 (an SNF2 domain-containing protein) are required for this mobile silencing effect based on the characterization of nrpd1, rdr2, and clsy1 mutants. Here, we characterize an additional mutant, jam39, with a similar phenotype of reduced photobleaching and lower levels of PDS siRNAs (Fig. 1). We mapped jam39 to At4g20400, which encodes the predicted JMJ14 protein with Jumonji C (JmjC), JmjN, $\mathrm{C} 5 \mathrm{HC} 2$ Zinc finger, $\mathrm{F} / \mathrm{Y}$-rich $\mathrm{C}$ terminus, and $\mathrm{F} / \mathrm{Y}$-rich $\mathrm{N}$
A

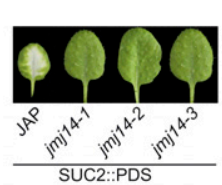

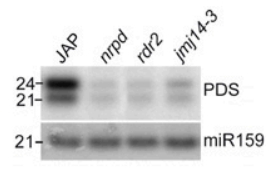

C

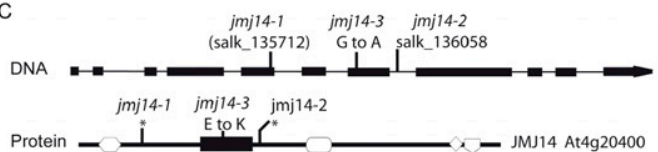

D
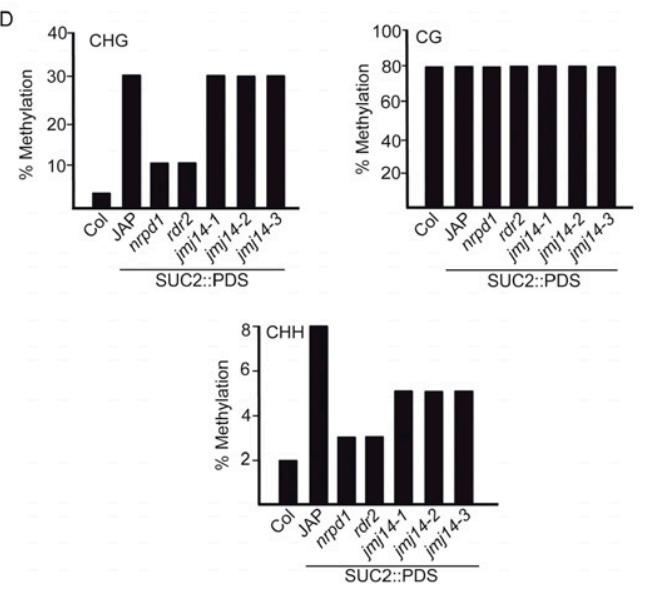

Figure 1. JMJ14/JAM39 is required for SUC2-PDS (JAP)-induced silencing of PDS and DNA methylation. $(A)$ Leaf phenotypes in JAP background. (B) Detection of PDS siRNAs in jam39/jmi14-3 and controls nrpd1 and $r d r 2$. (C) Schematic representation of JMJ14 locus and protein. Thick lines indicate exons and thin lines indicate introns. Protein domains shown are JmjN (white hexagon), JmjC (black rectangle), C5HC2 Zinc finger (white oval), FYRN (white diamond), and FYRC (white pentagon). (D) Cytosine methylation at the endogenous PDS locus assayed by bisulphite sequencing. At least 18 clones were analyzed for each line. terminus domains (Fig. 1). At4g20400 was first named as JMJ14 (Lu et al. 2008), and subsequently as JMJ4 (Jeong et al. 2009) and PKDM7B (Yang et al. 2010). We acknowledge precedence and follow the Lu et al. (2008) nomenclature.

To confirm jam39 was due to mutation of At4g20400/ JMJ14, we complemented the mutant phenotype of jam39 by transformation with a fragment of At4g20400 consisting of the promoter, coding region, and $3^{\prime}$ untranslated region (UTR) (Supplemental Fig. 1). We also demonstrated that two T-DNA insertion alleles, jmj14-1 (salk_135712) and jmi14-2 (salk_136058), had a loss of photobleaching phenotype in the presence of the JAP transgene (Fig. 1). The mutant from our screen is jmi14-3.

Sequence alignment of JMJ14 and four other closely related proteins-AtJMJ15/MEE27/At2g34880, AtJMJ16/ At1g08620, AtJMJ18/At1g30810, and AtJMJ19/ At2g38950-revealed a high degree of similarity to the KDM5/JARID1 subgroup of JmjC proteins (Supplemental Fig. 2; Lu et al. 2008) in the JmjC domain and in a 61amino-acid C5HC2 Zinc finger domain (Supplemental Fig. 3). The $\mathrm{C} 5 \mathrm{HC} 2$ domain has eight potential zinc ligand-binding residues, and may bind DNA or RNA. However, unlike the KDM5/JARID1 group, JMJ14 lacks a PHD domain that preferentially binds H3K9me3 (Iwase et al. 2007), and it has FYRN and FYRC domains at the $\mathrm{N}$ and C termini (Supplemental Fig. 3). Interestingly FYRN and FYRC domains are normally found in trithorax and its homologs, a group of histone H3K4 methyltransferases (Finn et al. 2006).

Crystal structure of a KDM4A/JHDM3A catalytic core sequence shows that $\mathrm{Fe}(\mathrm{II})$ is chelated by three residues (His188, Glu190, and His276) within the JmjC domain (Supplemental Fig. 3). Two additional residues (Thr185 and Lys206) are required for $\alpha \mathrm{KG}$ binding (Chen et al. 2006; Klose et al. 2006). Substitutions of the Glu that binds to $\mathrm{Fe}(\mathrm{II})$ to Asp, the Thr that binds to $\alpha \mathrm{KG}$ to Tyr or Phe, and the Lys that binds to $\alpha \mathrm{KG}$ to Arg are compatible with histone demethylation activity (Klose et al. 2006; Agger et al. 2007; De Santa et al. 2007; Hong et al. 2007; Lan et al. 2007). Based on these combined observations, we predicted that JMJ14 has H3K4 histone demethylation activity that is dependent on these conserved Fe(II)- and $\alpha$ KG-binding amino acids (Supplemental Fig. 3). This prediction has been confirmed recently by in vivo and in vitro analysis of JMJ14 (Jeong et al. 2009; Lu et al. 2010).

\section{IMJ14 acts at a far downstream stage of RNA silencing pathway mutants}

Previously, we identified non-CG DNA methylation at the endogenous $P D S$ locus in a region complementary to the JAP transgene. NRPD1 is required for non-CG (CHG and $\mathrm{CHH}$ ) methylation and $J A P$-induced photobleaching (Smith et al. 2007). In jmj14 mutants, based on bisulphite sequence analysis, we found that the $\mathrm{CHH}$ methylation at this endogenous PDS locus was reduced by as much as in nrpd1 and rdr2 (Fig. 1). In contrast, CHG methylation was not affected in jmj14 mutants, and was similar to the wild-type control with the JAP transgene (Fig. 1). As expected, nrpd1 and $r d r 2$ mutants had reduced amounts of CHG methylation at the endogenous PDS (Fig. 1). CG sites were highly methylated in wild type and all mutants, jmj14, nrpd1, and $r d r 2$ (Fig. 1). From this result, we infer that JMJ14 may act at the effector stage of RNA silencing rather than siRNA biogenesis and, based on the 
similarity of this protein to a histone demethylase, we propose that it may influence epigenetic modification of targeted DNA.

Based on epistatic interactions affecting the subcellular localization of proteins, the components of the Pol IV silencing pathway act in the sequence (NRPD1/CLSY1)RDR2-DCL3-AGO4-NRPE1 (Pontes et al. 2006). Therefore, to place JMJ14 in the silencing pathway, we analyzed the subcellular localization of RDR2 and AGO4 in nuclei of wild type and jmj14 mutants. Upstream silencing component RDR2 forms a crescent along the inner perimeter of the nucleolus and at foci throughout the nucleus (Pontes et al. 2006) in wild-type plants that was unaffected in jmi14 mutants. AGO4 localizes to nucleolus-adjacent Cajal bodies and nuclear foci, called $\mathrm{AB}$ bodies (Li et al. 2006; Pontes et al. 2006), and this pattern was also unaffected in most of the imj14 and the JAP nuclei examined (Fig. 2). These results are therefore
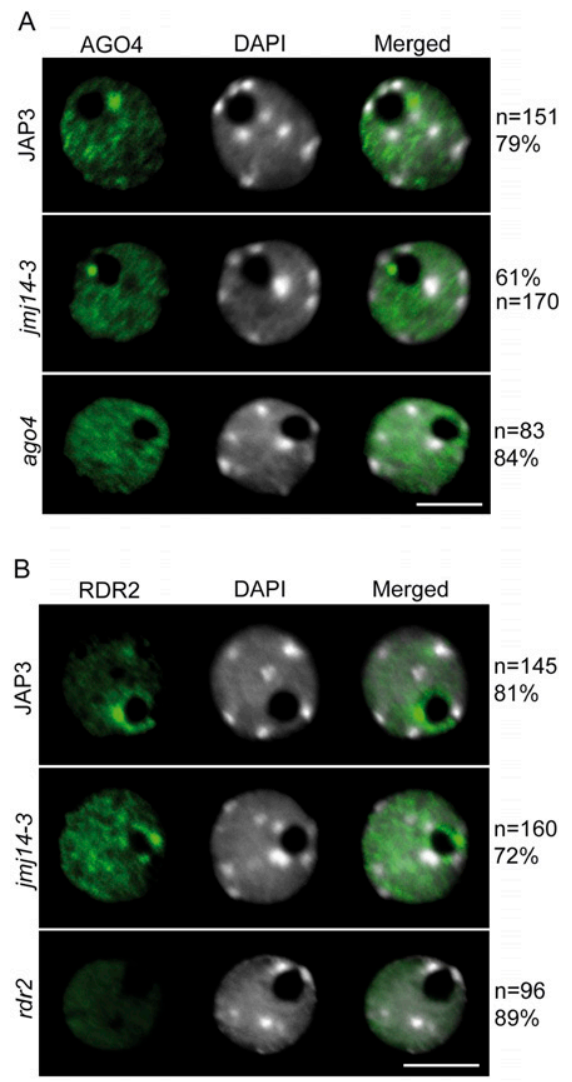

C

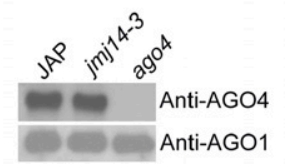

Figure 2. Nuclear localization of effector components AGO4 and RDR2 are not perturbed in jmj14. (A) Immunolocalization of AGO4 was performed on nuclei derived from JAP3 and mutants jmj14-3 and ago4. DAPI was used as a DNA counterstain. $(B)$ Immunolocalization of RDR2 was performed on JAP3, and mutants jmj14-3 and rdr2. $n=$ number of nuclei analyzed; $(\%)$ percentage of nuclei with representative immunolocalization pattern. Bar, $5 \mu \mathrm{m}$. $(C)$ Detection of AGO4 protein abundance by Western analysis. AGO1 abundance was used as a loading control. consistent with the hypothesis that JMJC14 acts far downstream from siRNA biogenesis in the silencing pathway.

To confirm this conclusion, we used Western blotting to assess the accumulation of AGO4 in the jmi14 mutants. AGO4 is less abundant in nrpd1 and rdr2 mutants, indicating that there is a link between the accumulation of the AGO4 effector of silencing and upstream siRNA biogenesis (Li et al. 2006; Pontes et al. 2006). In contrast, in jmi14 mutants, the AGO4 protein levels were similar in jmi14 and wild type (Fig. 2), consistent with the action of this protein in the downstream part of the JAP transgene silencing pathway.

In a further test, we recombined jmj14 with ago4 in the JAP background. Single ago4 mutants exhibited enhanced photobleaching that is not affected by loss of function in either RDR2 or CLSY1 (Smith et al. 2007). Our interpretation of this result is that AGO4 mediates self-silencing of the JAP transgene. The enhanced phenotype in the single ago4/mutants is because this self-silencing pathway is perturbed, and it persists in the double mutants because the requirement for upstream proteins RDR2 and CLSY1 is bypassed. If JMJ14 acts in the upstream part of the pathway, like RDR2 or CLSY1, then the jmj14 ago4 double mutant would exhibit the enhanced silencing phenotype. However, it did not: The enhanced silencing was greatly reduced (Fig. 3). This double-mutant analysis is therefore a further confirmation that JMJ14 acts in the downstream part of the $J A P$ silencing pathway.

The effect of JMI14 on endogenous RNA, DNA methylation, and flowering

To find out whether JMJ14 also affects silencing at endogenous loci, we used high-throughput sequencing of siRNA from seedling and floral tissues in wild-type and jmi14 plants. However, there were no loci at which JMJ14 had a significant effect. This lack of an effect was confirmed by small RNA Northern analysis of selected microRNAs (miRNAs), trans-acting siRNAs (tasiRNAs), and siRNAs (Fig. 4). From these data, it seemed likely that JMJ14 acts similarly to RNA-binding regulators of flowering FCA and FPA (Baurle et al. 2007): These proteins are required for JAP-induced photobleaching and transgenedirected methylation of the endogenous PDS DNA, but they did not affect the abundance of endogenous siRNA.

The similar action of JMJ14 and these flowering time regulators was reinforced by the analysis of long RNA transcripts of retrotransposons AtSN1 and Solo LTR (long terminal repeat) by quantitative RT-PCR. These long RNAs are up-regulated in $f p a$ and $f c a$ plants (Baurle et al. 2007), and they are similarly increased in jmj14 mutants. AtSN1 RNA was increased 75-fold more than wild type in jmj14 and nrpd1 mutants. A solo LTR was severalhundred-fold more abundant than wild type in jmi14 and nrpd1 mutants (Fig. 4).

Intergenic region 1 (IG1) RNA is also a target of the RNA silencing pathway that affects AtSN1 and Solo LTR. The IG1 RNA is up-regulated in nrpd1 and jmi14 mutants, although the abundance of the associated small RNAs (Huettel et al. 2006) in sequence data sets was not affected by JMJ14 function. However, it was striking that the long IG1 RNA increased to a greater extent in jmi14 mutants (Fig. 4) than in nrpd1.

The activation of AtSN1 and Solo LTR in jmj14 is also associated with loss of symmetric and asymmetric DNA 


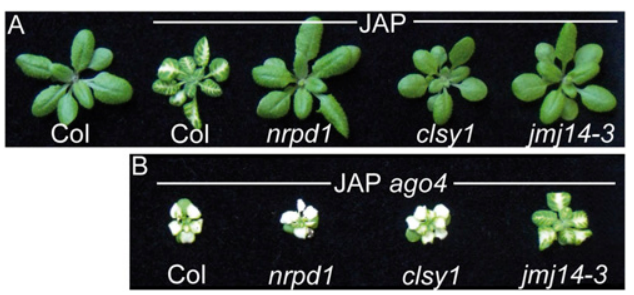

Figure 3. JMJ14 and not NRPD1A is required for JAP-induced enhanced photobleaching. (A) Single mutants nrpd1, clsy1, or jmj14-3 in a JAP background. Controls plants Col and JAP are also shown. (B) Double mutants of nrpd1, clsy1, or jmj14 in an ago4 JAP genetic background. Control plant JAP ago4 is also shown. All plants were grown under long-day conditions.

methylation at the corresponding genomic loci (Hamilton et al. 2002), as found previously in nrpd1 (Herr et al. 2005). Using an assay that combines digestion of genomic DNA using DNA methylation-sensitive restriction enzymes and semiquantitative PCR (Fig. 3), we found a loss of DNA methylation at these loci in jmi14 similar to nrpd1. We also assayed DNA methylation at solo LTRs using the PCR assay and found a loss of DNA methylation in jmi14 similar to nrpd1 (Fig. 4).

A link between JMJ14 and FPA/FCA was made through our observations that all three genes affect flowering. However, under long- and short-day conditions, the jmj14 mutants flowered earlier than the controls, approximately six rosette leaves, respectively (Fig. 5), whereas $f c a$ and $f p a$ mutants were later flowering (Quesada et al. 2003). This difference can be explained by the distinct activity of FPA/FCA and JMJ14 on the flowering time pathways. FPA/FCA suppress the FLC master regulator of flowering (Quesada et al. 2003), whereas JMJ14 does not affect FLC. Instead, it promotes expression of a second regulator, FT (Jeong et al. 2009; Lu et al. 2010).

\section{JMJ14 in chromatin silencing}

A straightforward interpretation of the results presented here invokes JMJ14 in the downstream part of silencing pathways that affect various endogenous loci, including PDS, AtSN1, Solo LTR, and IG1 (Fig. 3). Presumably, as JMJ14 is a histone H3K4 demethylase (Supplemental Fig. 2; Jeong et al. 2009; Lu et al. 2010), its role would lead to the loss of activating epigenetic marks associated with H3K4 methylation at the chromatin of target loci. This interpretation therefore implies that RNA silencing at AtSN1, Solo LTR, IG1, and PDS is either transcriptional or cotranscriptional, and is influenced by structural changes at the chromatin level.

Loss of a positive epigenetic mark is normally associated with gain of a negative mark at either the chromatin or DNA level and, consistent with this idea, there is increased methylation of DNA at AtSN1, Solo LTR, and $P D S$ target loci (Figs. 1, 4). At the PDS transgene locus, this change could be indirect and influenced by reduced siRNA production in the jmj14 mutants (Fig. 1). However, at the endogenous loci, where the level of siRNA is unaffected by the JMJ14 mutations (Fig. 4), there may be a more direct linkage. Inactivating epigenetic marks associated with modification of H3K9 or H3K27 might also be involved, and so that loss of the corresponding histone methyltransferase functions would give loss of the PDS silencing phenotype in the JAP lines. However, mutation of histone methyltransferase KYP had no effect on the PDS silencing phenotype (data not shown), and one of the other Arabidopsis SRA/SET domain proteins might be involved.

It is striking that mutation of JMJ14 has no effect on siRNA production from endogenous loci, but it does influence the level of siRNA from the PDS loci (Figs. 1, 3). To account for this observation, there must be a difference between the response of the endogenous and transgene loci to JMJ14-mediated epigenetic modification. Presumably, the endogenous AtSN1 and Solo LTR loci produce siRNA irrespective of whether JMJ14 is active, whereas the JAP transgene must be a better source of siRNA in the presence rather than the absence of active JMJ14. According to this idea, the IAP transgene would differ from the endogenous AtSN1 and Solo LTR loci in that there would be a positive feedback system affecting siRNA production. Silencing at all of these loci would be affected by JMJ14 acting at the downstream effector step. However, the silencing of the PDS locus would be reinforced in the presence of JMJ14 if the loss of the H3K4-activating epigenetic mark promoted further rounds of sRNA production.
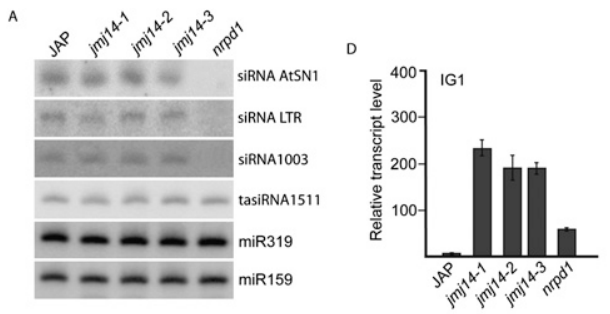

B
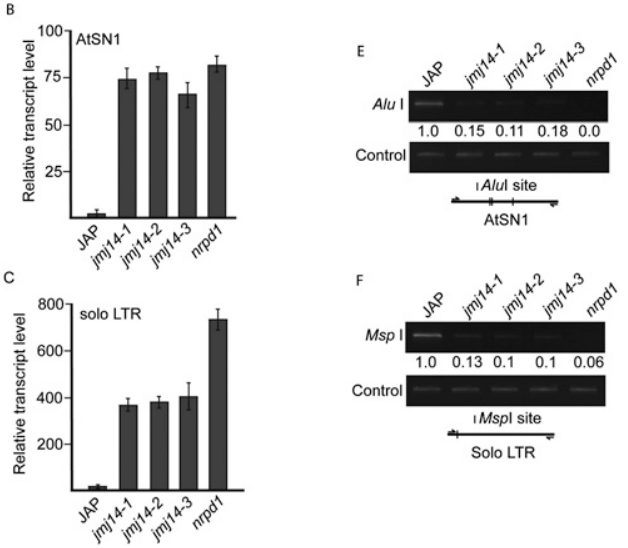

Figure 4. Characterization of endogenous siRNAs and detection of increased AtSN1, solo LTR, and IG1 abundance in jmi14. (A) Detection of siRNAs derived from AtSN1, LTR, 5S, tasiRNA 1511, and miRNAs 159 and 319 in JAP3, jmi14, and nrpd1 mutants. $(B)$ Detection of AtSN1 transcripts in JAP, jmi14, and nrpd1 mutants by quantitative PCR. $(C, D)$ Detection of solo LTR abundance $(C)$ and IG1 abundance $(D)$ by quantitative PCR. $(E)$ Analysis of DNA methylation at AtSN1 by PCR. AluI digestion is sensitive to cytosine methylation. Reduction of methylation results in reduced levels of the PCR product. $(F)$ Analysis of DNA methylation at solo LTR. MspI digestion is sensitive to cytosine methylation. Quantification of triplicate samples was performed, of which one representative sample is shown. 
Searle et al.

A

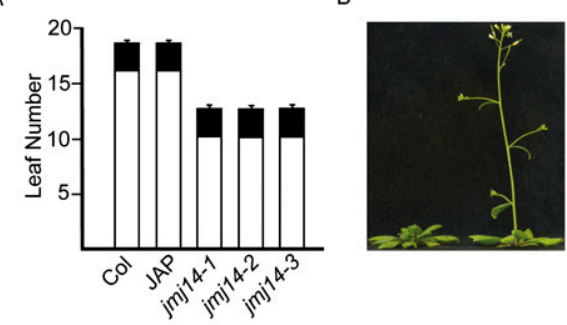

C

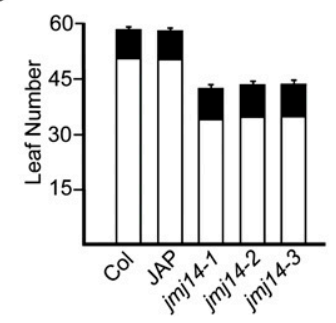

Figure 5. Flowering time of jmj14 mutants and controls Columbia and JAP. $(A)$ Average leaf number of plants grown under long-day photoperiod conditions. White bars indicate rosette, and the black bar indicates cauline leaves. (B) Representative Columbia and jmj14-3 plants grown under long-day conditions. Roots were removed for photographing. $(C)$ Average leaf of plants grown under short-day conditions. Average flowering time was calculated from at least 16 plants, and error bars show standard deviations.

\section{Materials and methods}

\section{Plant material}

Transgenic Arabidopsis thaliana (Columbia ecotype) SUC2-PDS line \#3, described here as JAP, was described previously (Smith et al. 2007). JMJ14/ At4g20400 alleles described are as follows: jmj14-1 is Salk_135712, jmj14-2 is SALK_136058, and jmj14-3 is an EMS-induced mutation. Allele jmi14-3 was a G-to-A transition changing conserved amino acid 387 from Glu to Lys, and was detected by a PCR and restriction enzyme digestion assay. EcoRI digestion of the PCR product amplified using oligonucleotide primers CCTTGAAGAACAGCCTGACTTG and GCTCCCAGAGGCA GTAAGTAG revealed two products, 200 and 264 bp, in Columbia, and a single 464 product in jmj14-3. Mutant alleles used were ago4 (ago4-3), nrpd1 (nrpd1a-5), nrpd1e (drd3-1), and rdr2-5.

\section{Plasmid constructs}

A complementing 6.2-kb genomic clone of JMJ14/At4g20400 was amplified using oligonucleotide primers attB1 (AGCAACATGTGTGTGACC) and attB2 (GATCTAGACGAGGATGATCTCAC), cloned into pGGW2$35 \mathrm{~S}$ and transformed into imj14-3 using Agrobacterium tumefaciens GV3101-mediated transformation. Vector pGGW2-35S was constructed after XbaI digestion of pGGW2 to remove the 35SCaMV promoter and self-ligation of the remaining vector. Gateway recombination sequence $a t t \mathrm{~B} 1$ is ACAAGTTTGTACAAAAAAGCAGGCT and attB2 is ACCCAG CTTTCTTGTACAAAGTGGT.

\section{RNA and protein analysis}

Solexa small RNA cloning was performed using Illumina Solexa kit as described by the manufacturer. Total RNA was isolated from 10-d-old seedlings, and $\sim 10 \mu \mathrm{g}$ of mirVana (Ambion)-purified RNA was used for ligation to adapters and amplification of small RNA fragments. Illumina sequencing was performed at Cambridge Research Institute UK, Cambridge. RT-PCR was performed using an Invitrogen SuperScript III kit as per the manufacturer's recommendations using $5 \mu \mathrm{g}$ of total RNA and with oligo-dT. RT-PCR detection of the JAP transgene was described previously (Smith et al. 2007). RT-PCR detection of JMJ14 mRNA was performed using primers GGGCTTGAAATGTTTGGATTTCTC and
CTTCAACAGTCCACGCAGAAGC. RT-PCR detection of retrotransposon AtSN1 and DNA transposon AtMul by RT-PCR was described previously (Herr et al. 2005; Baurle et al. 2007). Nuclear immunolocalization of proteins AGO4 and RDR2 was performed as described (Pontes et al. 2006).

\section{Acknowledgments}

We thank the Genomics and Bioinformatics core facilities (CRUK Cambridge Research Institute) for Illumina sequencing. This work was supported by the Gatsby Charitable Foundation and the EU Sixth Framework Programme Integrated Project SIROCCO (LSHG-CT-2006037900). O.P. was supported by the Edward Mallinckrodt Jr. Foundation. I.S. received a Marie Curie Incoming International post-doctoral fellowship and a Wellcome Trust VlP Award. D.C.B. is supported as a Royal Society Research Professor. C.W.M is funded by Commonwealth and NSERC scholarships. Experiments were designed by I.S. and D.C.B., and were performed by I.S, O.P., L.M.S., and C.W.M. The manuscript was prepared by I.S., C.W.M., and D.C.B.

\section{References}

Agger K, Cloos PAC, Christensen J, Pasini D, Rose S, Rappsilber J, Issaeva I, Canaani E, Salcini AE, Helin K. 2007. UTX and JMJD3 are histone H3K27 demethylases involved in HOX gene regulation and development. Nature 449: 731-734.

Baurle I, Smith LMA, Baulcombe DC, Dean C. 2007. Widespread role for the flowering time regulators FCA and FPA in siRNA-directed chromatin silencing. Science 318: 109-112.

Cao X, Jacobsen SE. 2002a. Locus-specific control of asymmetric and CpNpG methylation by the DRM and CMT3 methyltransferase genes. Proc Natl Acad Sci 99: 16491-16498.

Cao XF, Jacobsen SE. 2002b. Role of the Arabidopsis DRM methyltransferases in de novo DNA methylation and gene silencing. Curr Biol 12: $1138-1144$.

Chen ZZ, Zang JY, Whetstine J, Hong X, Davrazou F, Kutateladze TG, Simpson M, Mao QL, Pan CH, Dai SD, et al. 2006. Structural insights into histone demethylation by JMJD2 family members. Cell 125: 691702 .

Christensen I, Agger K, Cloos PAC, Pasini D, Rose S, Sennels L, Rappsilber J, Hansen KH, Salcini AE, Helin K. 2007. RBP2 belongs to a family of demethylases, specific for tri-and dimethylated lysine 4 on histone 3. Cell 128: 1063-1076.

De Santa F, Totaro MG, Prosperini E, Notarbartolo S, Testa G, Natoli G. 2007. The histone H3 lysine-27 demethylase Jmjd3 links inflammation to inhibition of polycomb-mediated gene silencing. Cell 130: 1083-1094.

Ebbs ML, Bender J. 2006. Locus-specific control of DNA methylation by the Arabidopsis SUVH5 histone methyltransferase. Plant Cell 18: 1166-1176.

Ebbs ML, Bartee L, Bender J. 2005. H3 lysine 9 methylation is maintained on a transcribed inverted repeat by combined action of SUVH6 and SUVH4 methyltransferases. Mol Cell Biol 25: 10507-10515.

Finn RD, Mistry J, Schuster-Bockler B, Griffiths-Jones S, Hollich V, Lassmann T, Moxon S, Marshall M, Khanna A, Durbin R, et al. 2006. Pfam: Clans, Web tools and services. Nucleic Acids Res 34: 247-251.

Hamilton AJ, Voinnet O, Chappell L, Baulcombe DC. 2002. Two classes of short interfering RNA in RNA silencing. EMBO J 21: 4671-4679.

Herr AJ. 2005. Pathways through the small RNA world of plants. FEBS Lett 579: 5879-5888.

Herr AJ, Jensen MB, Dalmay T, Baulcombe D. 2005. RNA polymerase IV directs silencing of endogenous DNA. Science 308: 118-120.

Hong SH, Cho YW, Yu LR, Yu H, Veenstra TD, Ge K. 2007. Identification of JmjC domain-containing UTX and JMJD3 as histone H3 lysine 27 demethylases. Proc Natl Acad Sci 104: 18439-18444.

Huang L, Jones AM, Searle I, Patel K, Vogler H, Hubner NC, Baulcombe DC. 2009. An atypical RNA polymerase involved in RNA silencing shares small subunits with RNA polymerase II. Nat Struct Mol Biol 16: 91-93.

Huettel B, Kanno T, Daxinger L, Aufsatz W, Matzke AJM, Matzke M. 2006. Endogenous targets of RNA-directed DNA methylation and Pol IV in Arabidopsis. EMBO I 25: 2828-2836. 
Iwase S, Lan F, Bayliss P, de la Torre-Ubieta L, Huarte M, Qi HH, Whetstine JR, Bonni A, Roberts TM, Shi Y. 2007. The X-linked mental retardation gene SMCX.JARID1C defines a family of histone H3 lysine 4 demethylases. Cell 128: 1077-1088.

Jackson JP, Lindroth AM, Cao XF, Jacobsen SE. 2002. Control of CpNpG DNA methylation by the KRYPTONITE histone H3 methyltransferase. Nature 416: 556-560.

Jeong JH, Song HR, Ko JH, Jeong YM, Kwon YE, Seol JH, Amasino RM, Noh B, Noh YS. 2009. Repression of FLOWERING LOCUS T chromatin by functionally redundant histone $\mathrm{H} 3$ lysine 4 demethylases in Arabidopsis. PLoS One 4: 379-384.

Johnson LM, Bostick M, Zhang X, Kraft E, Henderson I, Callis J, Jacobsen SE. 2007. The SRA methyl-cytosine-binding domain links DNA and histone methylation. Curr Biol 17: 379-384.

Kanno T, Aufsatz W, Jaligot E, Mette MF, Matzke M, Matzke AJ. 2005a. A SNF2-like protein facilitates dynamic control of DNA methylation. EMBO Rep 6: 649-655.

Kanno T, Huettel B, Mette MF, Aufsatz W, Jaligot E, Daxinger L, Kreil DP, Matzke M, Matzke AJ. 2005b. Atypical RNA polymerase subunits required for RNA-directed DNA methylation. Nat Genet 37: 761765.

Klose RJ, Kallin EM, Zhang Y. 2006. JmjC-domain-containing proteins and histone demethylation. Nat Rev Genet 7: 715-727.

Lahmy S, Pontier D, Cavel E, Vega D, El-Shami M, Kanno T, Lagrange T. 2009. PolV(PolIVb) function in RNA-directed DNA methylation requires the conserved active site and an additional plant-specific subunit. Proc Nat1 Acad Sci 106: 941-946.

Lan F, Bayliss PE, Rinn JL, Whetstine JR, Wang JK, Chen SZ, Iwase S, Alpatov R, Issaeva I, Canaani E, et al. 2007. A histone H3 lysine 27 demethylase regulates animal posterior development. Nature 449: 689-694.

Lee MG, Norman J, Shilatifard A, Shiekhattar R. 2007. Physical and functional association of a trimethyl H3K4 demethylase and Ring6a/ MBLR, a polycomb-like protein. Cell 128: 877-887.

Li CF, Pontes O, El-Shami M, Henderson IR, Bernatavichute YV, Chan SWL, Lagrange T, Pikaard C, Jacobsen SE. 2006. An ARGONAUTE4containing nuclear processing center colocalized with cajal bodies in Arabidopsis thaliana. Cell 126: 93-106.

Lindroth AM, Shultis D, Jasencakova Z, Fuchs I, Johnson L, Schubert D, Patnaik D, Pradhan S, Goodrich J, Schubert I, et al. 2004. Dual histone H3 methylation marks at lysines 9 and 27 required for interaction with CHROMOMETHYLASE3. EMBO I 23: 4146-4155.

Lu F, Li G, Cui X, Liu C, Wang XJ, Cao X. 2008. Comparative analysis of JmjC domain-containing proteins reveals the potential histone demethylases in Arabidopsis and rice. J Integr Plant Biol 50: 886-896.

Lu F, Cui X, Zhang S, Liu C, Cao X. 2010. JMJ14 is an H3K4 demethylase regulating flowering time in Arabidopsis. Cell Res 20: 387-390.

Noh B, Lee SH, Kim HJ, Yi G, Shin EA, Lee M, Jung KJ, Doyle MR, Amasino RM, Noh YS. 2004. Divergent roles of a pair of homologous jumonji/zinc-finger-class transcription factor proteins in the regulation of Arabidopsis flowering time. Plant Cell 16: 2601-2613.

Pagnussat GC, Yu HJ, Ngo QA, Rajani S, Mayalagu S, Johnson CS, Capron A, Xie LF, Ye D, Sundaresan V. 2005. Genetic and molecular identification of genes required for female gametophyte development and function in Arabidopsis. Development 132: 603-614.

Palauqui JC, Elmayan T, Pollien JM, Vaucheret H. 1997. Systemic acquired silencing: Transgene-specific post-transcriptional silencing is transmitted by grafting from silenced stocks to non-silenced scions. EMBO J 16: 4738-4745.

Pontes O, Li CF, Nunes PC, Haag JR, Ream T, Vitins A, Jacobsen SE, Pikaard CS. 2006. The Arabidopsis chromatin-modifying nuclear siRNA pathway involves a nucleolar RNA processing center. Cell 126: 79-92.

Quesada V, Macknight R, Dean C, Simpson GG. 2003. Autoregulation of FCA pre-mRNA processing controls Arabidopsis flowering time. EMBO J 22: 3142-3152.

Saze H, Shiraishi A, Miura A, Kakutani T. 2008. Control of genic DNA methylation by a jmjC domain-containing protein in Arabidopsis thaliana. Science 319: 462-465.

Seward DJ, Cubberley G, Kim S, Schonewald M, Zhang L, Tripet B, Bentley DL. 2007. Demethylation of trimethylated histone H3 Lys4 in vivo by JARID1 JmjC proteins. Nat Struct Mol Biol 14: 240-242.
Shi YJ, Lan F, Matson C, Mulligan P, Whetstine JR, Cole PA, Casero RA, Shi Y. 2004. Histone demethylation mediated by the nuclear arnine oxidase homolog LSD1. Cell 119: 941-953.

Smith LM, Pontes O, Searle I, Yelina NE, Yousafzai FK, Herr AJ, Pikaard C, Baulcombe D. 2007. A novel SNF2 protein associated with nuclear RNA silencing and spread of a silencing signal between cells in Arabidopsis. Plant Cell 19: 1507-1521.

Voinnet O, Baulcombe DC. 1997. Systemic signalling in gene silencing. Nature 389: 553.

Voinnet O, Vain P, Angell S, Baulcombe DC. 1998. Systemic spread of sequence-specific transgene RNA degradation is initiated by localized introduction of ectopic promoterless DNA. Cell 95: 177-187.

Yang W, Jiang D, Jiang J, He Y. 2010. A plant-specific histone H3 lysine 4 demethylase represses the floral transition in Arabidopsis. Plant $J$. doi: 10.1111/j.1365-313X.2010.04182.x. 


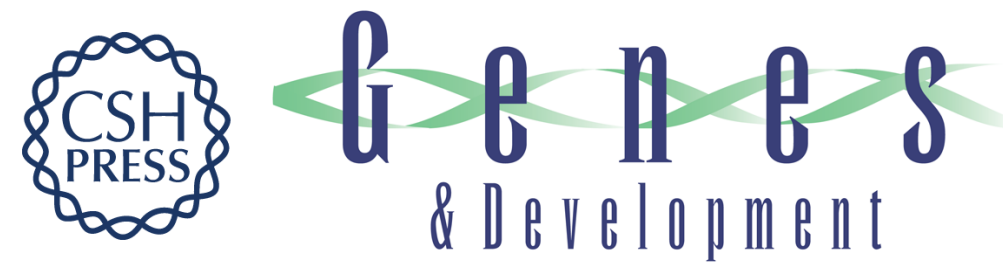

\section{JMJ14, a JmjC domain protein, is required for RNA silencing and cell-to-cell movement of an RNA silencing signal in Arabidopsis}

lain R. Searle, Olga Pontes, Charles W. Melnyk, et al.

Genes Dev. 2010, 24:

Access the most recent version at doi:10.1101/gad.579910

Supplemental http://genesdev.cshlp.org/content/suppl/2010/05/05/24.10.986.DC1
Material

References This article cites 41 articles, 16 of which can be accessed free at:

http://genesdev.cshlp.org/content/24/10/986.full.html\#ref-list-1

License

Email Alerting Receive free email alerts when new articles cite this article - sign up in the box at the top

Service right corner of the article or click here.

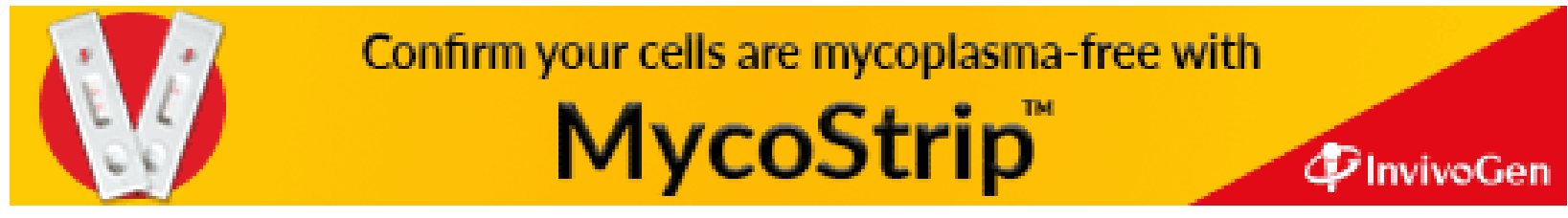

